\title{
Literacy and Language of Instruction in Nigeria: A Case Study of Integrated Science Teaching in Selected Primary Schools
}

\author{
A. A. Asiyanbola \\ Mohammed Ademilokun
}

\begin{abstract}
Research has proven beyond a reasonable doubt that children can acquire knowledge better in their mother tongue (MT) or language of immediate environment (LIE) rather than in the second language (L2), which is often a colonial master's language, but also the recognized official language in the country. The present paper explores the functions of both the Indigenous language or mother tongue (e.g., Yoruba) and the official language (English) in the dissemination of education, particularly in the primary schools in Nigeria. It also discusses the policy statements on the two languages and their social realities or practices in the educational set-ups operating in the country. Using six private and public primary schools as a case study in Southwestern Nigeria, we found that codeswitching between English (L2) and Yoruba (MT) could be more effective than either of the languages alone, and that the MT or LIE should never be jettisoned in the education of the child, especially in teaching subjects other than English, such as Integrated Science.
\end{abstract}

Keywords: mother tongue; official language; second language; instruction; policy statements; implementation

\section{Introduction}

The specific objectives of the study are to identify and investigate the language(s) of instruction of Integrated Science in six selected primary schools in two of the four Ife Local Government Areas (henceforth LGAs). Second, the paper will consider the effectiveness and appropriateness or not of the language of instruction. The two Ife LGAs are Ife North, with its headquarters in Ipetumodu, and Ife East, with its headquarters at Oke-Ogbo. Ife Central and Ife South were omitted because of time constraints. All the selected LGAs are situated in Osun State in Southwestern Nigeria. The primary schools in these LGAs can be broadly classified as private and public. To ensure proper representativeness of the primary schools located in Nigeria, we have purposively selected three types of primary schools in every LGA, representing three further categories of primary schools found in the nooks and crannies of Nigeria in particular, and Africa in general: public but elitist, private and 
elitist, and public but not elitist. The public but elitist and the private and elitist charge tuition but the tuition in the latter is higher than the former. However, the public but not elitist schools do not charge tuition and most parents can afford to send their children and wards to such schools.

\section{Research Methodology}

The subjects of the study are mainly Primary Four (IV) pupils and their teachers in the selected primary schools. The test instruments are of two types: questionnaires on the teaching of Integrated Science (IS) for the teachers in the selected schools, and interview guides for pupils selected from each of the six schools under study:

\section{Questionaires for Teachers}

(a) What language do you use to teach IS?

(b) What language is stipulated in the National Policy on Education (NPE) for teaching IS in Primary IV?

(c) Are you aware of the language of instruction in Primary IV?

(d) Do your pupils comprehend your lessons in IS?

(e) What language do you recommend for the teaching of IS in primary schools?

Interview Guides for Pupils

(a) What language do you and your teacher use during Integrated Science (IS)?

(b) Do you understand IS better when taught in English than when taught in Yoruba?

(c) Do you understand IS better when taught in Yoruba than when taught in English?

(d) In what language do you write your answers during examinations?

(e) Do you like it when English is combined with Yoruba in teaching IS?

The number of pupils randomly selected from each school is thirty (30) with a mix of male and female. Also, the pupils are of mixed abilities: very superior, superior, average and poor. They average nine years of age. Our findings are quantified by using simple percentages, as shown in each of the tables generated from the study and in the data analysis and discussion.

\section{Types of Literacy}

Literacy traditionally involved three aspects: reading, writing and arithmetic (pronounced as rithmetic, to generate the nickname "the three Rs"). In modern times, however, the term literacy has been tremendously expanded in scope. According to Hornstein (2005),

So, educating for literacy in a democracy becomes both a function of what we teach and the contexts in which it is taught as well as extending beyond ourselves to the notions of creating a just and humane world. For me this means focusing on what Luke (1998) calls "multi-literacies" and includes print literacy, critical literacy, multi-cultural literacy, mathematical and statistical literacy, internet literacy and media literacy, all taught in a context 
that encourages dialogue, choice ownership and participation. Such literacies are not discreet (sic) and cannot be taught as such. Rather, these multi-literacies are continuous and intertwined. We can neither teach literacy, nor act as fully literate citizens without all of these pieces of literacy at once. A genuinely participatory democracy could function with no less from its citizenry and should expect no less from its school. (p. 2)

From the extract above, one can realize that print literacy, otherwise known as traditional literacy, is the one that is always emphasized as literacy. However, in modern times, there is also critical literacy, which involves the ability of the reader to see how various texts represent certain viewpoints and agendas, and to understand how such texts might seek to influence ideas, behavior, assumptions, or cultural perspectives. It implies that to be literate, we must bring our understandings of the world to the understanding of the text, because understanding the world is a process of conscious critical work. We are actually rewriting or transforming the world as we transform our understandings of the world and the text in relation to it (Hornstein, 2005, p. 4).

Multicultural literacy refers to "the skills and ability to identify the creators of knowledge and their interests, to uncover the assumptions of knowledge, to view knowledge from diverse ethnic and cultural perspectives and to use knowledge that will create a just and humane world" (Hornstein, 2005, p. 5). Technological literacy refers to how best to manipulate various machines in order to enjoy maximum benefits from them and also possibly avoiding the dangers inherent in using them. Mathematical and statistical literacy is one's ability to use and perform operations with numbers involving addition, subtraction, multiplication, and division. It involves various complex calculations needed to solve scientific problems of various kinds. To be mathematically and statistically literate, one must be able to communicate by sending and receiving information in this realm, and be able to show they understand it by giving the proper required response. Internet literacy involves one's knowledge of information and communication technology, and their ability to use it and acuity in understanding its language.

Media literacy involves critical utilization of mass media such as the radio, television, newspapers, magazines, journals, and books. In handling these mass media, citizens in a democracy should be able to sieve fact from fiction, and also to recognize opinions and agendas of individuals and certain political parties or other groups of people who are trying to influence us or make us come to their sides, even if their ideology is not popular. The question that arises from the foregoing is whether the child's mother tongue (MT) or language of immediate environment (LIE) is enough for him or her to attain all the aforementioned types of literacy in the 21st century. The answer is certainly no, but nevertheless, the MT or LIE of the child should not be neglected in his or her education, because it is the language of cognition and thought for the African child. 


\section{Language of Instruction in Nigerian Primary Schools}

The issue of language of instruction in the primary school has been a dicey one in Nigeria. According to the National Policy on Education statement, the language of instruction in the nursery school and the first two years of primary school should be the MT or LIE, and beyond that, English (see National Policy on Education [NPE] $1969,1971,1980,2004$ and 2013). But we have to note that there is no one-to-one correspondence to this language policy when it comes to implementation. What can be said is that it is the socioeconomic setting of the child's education that dictates the language of instruction for the child. For example, in an elitist setting, where the education and socioeconomic status of the parents are high, the language of instruction is English. But in a multilingual, poor socioeconomic setting, the language of instruction is either the MT or the LIE. The investigation of this social phenomenon is one of the objectives of the present paper.

In this light, many linguists and literacy scholars have investigated various languages of instruction-in particular, their efficiency-as prevalent in Nigerian primary schools (see Adefila, 2008; Jegede, 2009; Onwuka and Ohia, 2008; Okebukola 2008; Salami, 2008; Ugwanyi, 2008). It is not a surprise that we have many articles on language of instruction cited for 2008, as most of the papers were presented in the midterm conference of the Reading Association of Nigeria (RAN) held in Ibadan in 2007. This conference, organized by the International Development in Africa Committee (IDAC) of the International Reading Association (IRA) was a milestone in about thirty years of the existence of RAN as an organization. The conference witnessed, as it were, a crop of articles on the significance of the MT as a language of instruction in English as second language (ESL) situations. This event was after the RAN's biennial conference held in PortHarcourt, Nigeria in October 2006. It was then that literacy practitioners began to see the importance of the hitherto neglected MT or LIE in the education of the African child, who up till then had been subjected to unnecessary linguistic colonialism.

In addition, people's attitudes towards the learning and use of different types of languages have also been investigated (see Adekunle, 1995; Asiyanbola, 2009; Bamgbose, 1971, 1995, 2009; Bilewumo, 2008; Jowitt, 1995). According to Bamgbose (2009), on the language of instruction in Nigerian primary schools:

In a multilingual situation in which English is not the first language but is the medium of learning and teaching in schools, it has been repeatedly observed that a significant percentage of pupils repeat classes, drop out before the end of the elementary education cycle, or fail to obtain the required school leaving certification. Although several factors, including teachers' incompetence, learning environment, teaching materials and other facilities, financial capabilities of parents, and community support may affect success or failure in schools, the fact is that the medium of instruction is a significant factor. (p. 651) 
The extract above emphasizes the importance of the lack of the MT or LIE, if they are neglected for English (L2) in the education of the child. It is not uncommon, however, if the teacher sometimes makes recourse to the MT when he/she realizes that the learner cannot quickly grasp the subject matter in English; this is more frequent when the discipline imparted is not English as a subject. earlier:

Halliday (1973) hinted at the importance of language instruction even

[E]ducational failure is often, in a very general and rather deep sense, language failure. The child who does not succeed in the school system may be one who is not using language in the ways required by the school. In its simplest interpretation, this might seem to mean merely that the child cannot read or write or express him/herself adequately in speech. But these are externals of linguistic success, and it is likely that underlying the failure to master these skills is a deeper and more general problem, a fundamental mismatch between the child's linguistic capabilities and the demands that are made upon them. (p. 8)

With the above quotations, teachers, educational curriculum planners and the government should rethink the language aspect of instructional delivery in schools. While we have been using English-only as a medium of instruction, we need to look at the MT or LIE (e.g., Yoruba, Igbo, Igala, Ibibio, Ijaw, Hausa, Itshekiri, Urhobo, etc.), or at least a combination of MT and English, which Jegede (2008) and Salami (2008) referred to as a code-switching communicative strategy for imparting disseminating instruction.

Jegede's (2008) study investigates code-switching as a communicative strategy in multilingual mathematics classrooms in selected primary schools in IleIfe. It focuses specifically on the extent and effect of the use and role of languages in a multilingual mathematics classroom. Data were collected from five selected primary schools through ethnographic observation and structured interviews. The study, which used a matrix language framework (MLF), was able to identify Yoruba (MT) as the main or matrix language of instruction and English as the other embedded language of instruction in the code-switching (CS) communicative strategy proposed; it further found that the languages employed are effective. In addition, it challenges the view of CS as a sign of communicative incompetence.

\section{The Nature of Integrated Science as a School Subject}

Integrated Science comprises biology, physics and chemistry combined together for pupils in the primary and secondary schools in Nigeria. The same discipline may be referred to as General Science or Elementary Science or simply science. But the terms mean the same thing and have similar content.

Just like mathematics, the subject demands a lot of attention from pupils and teachers. The teachers need to devise an appropriate and effective method, such as using practical lessons, involving showing of real objects, dissection of animals to show various parts of its body, demonstration of several types of experiments, and the use of metalanguage always coined in Latin, Greek or English. As a result of the 
metalanguage, strict observation, formulation of hypotheses, experimentation to test the hypotheses, and formulation of law, some pupils find the subject very difficult to internalize, especially when all these processes are not carried out using the MT and LIE.

General Science or Integrated Science is the study of living and nonliving things. Biology, one of its branches, is the study of two types of living things: animals and plants. The study of plants is called botany, while the study of animals (higher and lower) is called zoology. Physics, on the other hand, is the study of matter in relation to energies and forces in the environment. The branches of physics are instrumental, measurement, biophysics, and industrial. Chemistry is the study of matter, anything that has mass and occupies a space. It is mainly the study of nonliving things.

Science is equally intertwined with mathematics and Higher Mathematics. Any pupil who wants to study any science discipline in the university is expected to be well versed in mathematics. It is a prerequisite to the study of any science-based course in the university or any higher institution. Similarly, in primary schools, we expect the pupil who is interested in science to have an affinity for mathematics or arithmetic. Learners are always categorized, especially in secondary schools, according to their mental capabilities in three areas: science-based, social sciencebased, and art/humanity-based. The bedrock of all these classifications is in the primary school, where pupils are normally exposed to all disciplines at this level for them to choose from when they get to secondary and tertiary institutions.

\section{Data Analysis and Discussion}

Our data analysis and discussion focus on the responses from the pupil-subjects and teacher-subjects in the six schools under study. The findings, however, can be extrapolated to teaching and learning situations in various parts of Nigeria, Africa and the world, especially in places where we have bilingual, bicultural, multilingual and multicultural speech communities.

\section{Pupil-Respondents' Data}

Five tables were generated from the responses of the pupil-subjects in line with the number of the questions in the pupils' interview guide. We will treat the data according to the order of the questions in the interview guide, as follows:

(a) What language do you and your teacher use during Integrated Science (IS)?

None of the pupils from the six schools under study indicated that they use Yoruba as a language of instruction. In School A (CAC Primary School, Edunabon), five pupils indicated that it was English that was most often used as the language of instruction during Integrated Science. That is about $33.3 \%$ of the whole population sample used for the study in that school. In Saint Paul's Ayegbaju, Ile-Ife (School B), ten out of 28 respondents, that is, $36 \%$ of the sample, indicated that English was most often used as the language of IS instruction. In the last two schools, Schools E and F (LA Primary School, Orugun and Saint Philip's Ayetoro respectively), none of 
the pupils indicated English as the language of IS instruction. However, it was a different story with regard to the use of Yoruba and English combined as languages of instruction in the IS classroom in most of the schools used for the study. For example, 10 pupils, about $67 \%$ of the sample taken from School A, indicated that they and their teachers used a combination of Yoruba and English as languages of instruction. Similarly, 18 (64\%) indicated that their teacher taught them using English and Yoruba simultaneously during IS lessons.

The story was not the same in School C (Faith Standard Nursery and Primary School, Iloro), which is a private highbrow school. None of the pupils indicated that they code-switched between English and Yoruba during IS lessons. In Paramount Nursery and Primary School (School D), however, in spite of being a private school, a huge percentage of the population sample, 25 (86.4\%), said their teacher codeswitched between English and Yoruba for them to understand IS lessons. In School $\mathrm{E}$, the entire population sample $(100 \%)$ indicated that they and their teacher often code-switched between English and Yoruba during IS lessons. Also, at Saint Philip's Ayetoro, which is a public school, all 28 pupils $(100 \%)$ that responded said both languages were being used as languages of IS instruction. The table below shows that the pupils that wanted the teaching and learning of IS to be in code-switched Yoruba and English outnumber those that wanted the teaching and learning of IS to be in monolingual English. For example, the total number of pupils that wanted the IS to be taught in code-switched English and Yoruba was 101 out of 130, while those who wanted English-only was 29 out of 130 . The ratio of pupils that wanted instruction in Integrated Science to be presented to them in a code-switch of Yoruba and English to those pupils that preferred English-only instruction is 78 to 22. This implies that the classroom teacher should exploit the MT or LIE in the dissemination of IS instruction in primary schools. It may, however, be combined with English, which is the official and examination language.

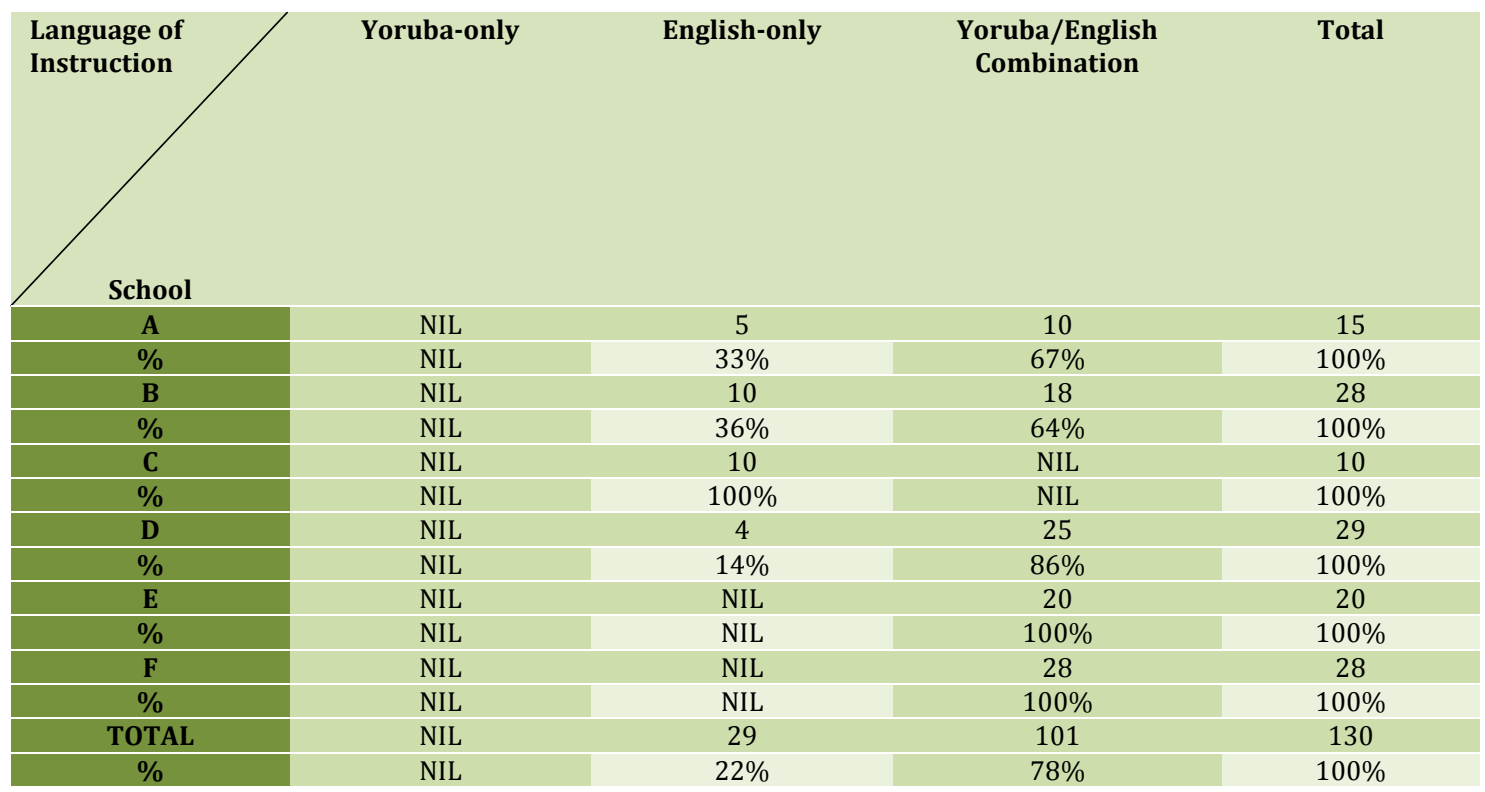

Table 1. Language of Instruction Preferred by Teachers and Pupils 
(a) Do you understand IS better when taught in English than when taught in Yoruba?

In School A, 15 (100\%) of the pupils said they understood IS better when taught in English than when taught in Yoruba. Only 5 (20\%) indicated YES to the question in School B, 10 (100\%) in School C, 25 (83.3\%) in School D, 4 (20\%) in School E and $28(100 \%)$ in School F, all claimed that they understood IS better when taught in English than when taught in Yoruba. No pupil claimed they understood IS better when taught in Yoruba than when taught in English in School A. Twenty pupils (80\%), however, said NO to the above question, while 5 pupils said NO to the question in School D. Sixteen (80\%) said NO to the above question in School E while none said NO in School F. In all, 87 (68\%) out of $128(100 \%)$ claimed that they preferred IS to be taught in English only, against 41 (32\%) that preferred it to be taught in the Yoruba mother tongue. This is just an issue of preference rather than efficiency. The pupils were apparently aware of the importance of English as the official and significant language of education, and as the power language in general in Nigeria. This, however, is not an index of a greater proficiency in English than in their MT.

\begin{tabular}{|c|c|c|c|}
\hline School & Yes & No & Total \\
\hline A & 15 & NIL & 15 \\
\hline$\%$ & $100 \%$ & NIL & $100 \%$ \\
\hline B & 5 & 20 & 25 \\
\hline$\%$ & $20 \%$ & $80 \%$ & $100 \%$ \\
\hline C & 10 & NIL & 10 \\
\hline$\%$ & $100 \%$ & NIL & $100 \%$ \\
\hline D & 25 & 5 & 30 \\
\hline$\%$ & $83 \%$ & $17 \%$ & $100 \%$ \\
\hline E & 4 & 16 & 20 \\
\hline$\%$ & $20 \%$ & $80 \%$ & $100 \%$ \\
\hline F & 28 & NIL & 28 \\
\hline$\%$ & $100 \%$ & NIL & $100 \%$ \\
\hline TOTAL & 87 & 41 & 128 \\
\hline \% & $68 \%$ & $32 \%$ & $100 \%$ \\
\hline
\end{tabular}

Table 2. Pupils' Attitudes to English as a Language of Instruction

(b) Do you understand IS better when taught in Yoruba than when taught in English?

No pupil said YES to the above question in School A. In School B, however, 20 (77\%) of the pupils said YES in response to it. Likewise, in School C, which is a highbrow nursery and primary school, none of the pupils indicated an affirmation. In School D, only 6 (21\%) pupils said YES to the question, while in School E, 14 (70\%) pupils indicated that they understood IS lessons better when taught in Yoruba than when taught in English. In School F, however, only one pupil said YES to the above question. In another vein, 14 (93.3\%) said NO to the question in School A, while 6 $(23 \%)$ said NO to the question in School B. In School C, 10 (100\%) indicated NO to the question, implying that that they did not support the idea of being taught IS in their mother tongue, Yoruba. Twenty-three (79\%) pupils indicated the answer NO 
in School D. In School E, only $6(30 \%)$ said NO to the question above, while 25 (96.1\%) in School F indicated that they did not want to be taught IS in Yoruba, which is their mother tongue. In all, 41 (33\%) out of 125 (100) preferred IS to be taught in Yoruba only, while 84 (67\%) wanted it to be taught in English.

\begin{tabular}{|c|c|c|c|}
\hline School & Yes & No & Total \\
\hline A & NIL & 14 & 14 \\
\hline$\%$ & NIL & $100 \%$ & $100 \%$ \\
\hline B & 20 & 6 & 26 \\
\hline$\%$ & $77 \%$ & $23 \%$ & $100 \%$ \\
\hline C & NIL & 10 & 10 \\
\hline \% & NIL & $100 \%$ & $100 \%$ \\
\hline D & 6 & 23 & 29 \\
\hline$\%$ & $21 \%$ & $79 \%$ & $100 \%$ \\
\hline E & 14 & 6 & 20 \\
\hline$\%$ & $70 \%$ & $30 \%$ & $100 \%$ \\
\hline F & 1 & 25 & 26 \\
\hline \% & $4 \%$ & $96 \%$ & $100 \%$ \\
\hline TOTAL & 41 & 84 & 125 \\
\hline \% & $33 \%$ & $67 \%$ & $100 \%$ \\
\hline
\end{tabular}

Table 3. Pupils' Attitude to Yoruba as Language of Instruction

(c) In what language do you write your answers during an examination?

Thirteen (100\%) pupils in School A indicated English as the language of examination. In School B, 27 (96\%) said English, and 10 (100\%) indicated English to be the language of examination in School C. While $20(77 \%)$ gave English as the language of examination in School D, all 18 pupils in School E (100\%) and all 27 $(100 \%)$ in School F reported using English. Only in School D) do we have 1 pupil $(4 \%)$ that indicated Yoruba (mother tongue), and 5 (19.2\%) who indicated a codeswitch of English and Yoruba as the language(s) of examination. There is no gainsaying the fact that English is the language of examination, as summarized in the table below. The pupils that responded that English was most often used as the language of examination outnumber those that said otherwise. Educators are aware of this fact, but what we are saying is that there is a need for code combination or switch between English and the pupils' MT when teaching in the classroom in order to facilitate the use of pupils' use of English on the examinations. 


\begin{tabular}{|c|c|c|c|c|}
\hline $\begin{array}{l}\text { Language of } \\
\text { Instruction }\end{array}$ & English-only & Yoruba-only & Combination & Total \\
\hline A & 13 & NIL & NIL & 13 \\
\hline$\%$ & $100 \%$ & NIL & NIL & $100 \%$ \\
\hline $\mathrm{B}$ & 27 & 1 & NIL & 28 \\
\hline$\%$ & $96 \%$ & $4 \%$ & NIL & $100 \%$ \\
\hline $\mathrm{C}$ & 10 & NIL & NIL & 10 \\
\hline$\%$ & $100 \%$ & NIL & NIL & $100 \%$ \\
\hline $\mathrm{D}$ & 20 & 1 & 5 & 26 \\
\hline$\%$ & $77 \%$ & $4 \%$ & $19 \%$ & $100 \%$ \\
\hline E & 18 & NIL & NIL & 18 \\
\hline$\%$ & $100 \%$ & NIL & NIL & $100 \%$ \\
\hline $\mathrm{F}$ & 27 & NIL & NIL & 27 \\
\hline$\%$ & $100 \%$ & NIL & NIL & $100 \%$ \\
\hline TOTAL & 115 & 2 & 5 & 122 \\
\hline$\%$ & $94 \%$ & $2 \%$ & $4 \%$ & $100 \%$ \\
\hline
\end{tabular}

Table 4: Pupils' Responses on Language of Examination

(d) Do you like a situation in which English is combined with Yoruba in teaching I.S?

Fourteen (100\%) pupils said YES to the above question in School A, $27(100 \%)$ pupils in School B, only 2 (20\%) in School C, 24 (89\%) in School D, 16 (94.1\%) in School E, and $26(100 \%)$ in School F. In three schools some pupils said NO to the question above: in School C, 8 (80\%); in School D, 3 (11\%); and in School E, $1(6 \%)$. The majority $(109$, or $90 \%)$ of the pupil-respondents wanted a combination of Yoruba and English in the dissemination of IS lessons, despite the fact that they recognized the importance of English as a HIGH language in Nigeria. A minority $(12$ or $10 \%$ ) of the pupils did not want the code-switch because of their better attitude to English rather than to Yoruba, even though they do not have much facility in it. 


\begin{tabular}{|c|c|c|c|}
\hline School & Yes & No & Total \\
\hline A & 14 & NIL & 14 \\
\hline$\%$ & $100 \%$ & NIL & $100 \%$ \\
\hline B & 27 & NIL & 27 \\
\hline$\%$ & $100 \%$ & NIL & $100 \%$ \\
\hline C & 2 & 8 & 10 \\
\hline$\%$ & $20 \%$ & $80 \%$ & $100 \%$ \\
\hline D & 24 & 3 & 27 \\
\hline$\%$ & $89 \%$ & $11 \%$ & $100 \%$ \\
\hline E & 16 & 1 & 17 \\
\hline$\%$ & $94 \%$ & $6 \%$ & $100 \%$ \\
\hline $\mathbf{F}$ & 26 & NIL & 26 \\
\hline$\%$ & $100 \%$ & NIL & $100 \%$ \\
\hline TOTAL & 109 & 12 & 121 \\
\hline$\%$ & $90 \%$ & $10 \%$ & $100 \%$ \\
\hline
\end{tabular}

Table 5. Pupils' Attitude to English/Yoruba Code-Switch as Medium of Instruction

\section{Teachers' Responses}

As in the previous section of the paper, we first present each of the questions on the questionnaire before we analyze the data of the teachers' responses collected for this study. The number of the teacher respondents varies from question to question as reflected in all of the tables presented below.

(a) What language do you use to teach IS?

In response to this question, 23 teachers out of 40 indicated that they teach IS in English. This is $58 \%$ of the teacher population sample used for this study. None of them indicated that they usually teach IS using their mother tongue, Yoruba, as the language of instruction. However, 17 (42\%) indicated that they always teach IS using a combination of their mother tongue and English, which is the second language of the southwestern Nigerian speech community. This is to say that while English is the clear preference, as reflected in the table below, the mother tongue, Yoruba cannot be discarded for the dissemination of knowledge, other than English Language as a subject. This is clearly shown by the fact that only a little less than half of the teachers (42\%) were interested in a code-switch of Yoruba and English during IS lessons.

\begin{tabular}{|l|c|c|}
\hline Language of Instruction & Numbers of Teachers & Percentage \\
\hline English & 23 & $58 \%$ \\
\hline Yoruba & NIL & 0 \\
\hline Combination & 17 & $42 \%$ \\
\hline Total & 40 & $100 \%$ \\
\hline
\end{tabular}

Table 6. Teachers' Responses on Preferred Language of Instruction for IS 
(b) What language is stipulated in the NPE for teaching IS in Primary IV?

According to the findings presented in the table below, 2 (4.9\%) out of 41 teacherrespondents left the column blank, implying that they did not know the answer to the question. In other words, it shows that they were not actually aware of the language of instruction for IS as stipulated in the National Policy on Education (NPE). Thirty-six of the 41 (87.8\%) indicated English as the answer. Two teachers (4.9\%), however, indicated that the mother tongue was stipulated to teach IS in Primary IV in Nigeria. Lastly, one teacher (2.4\%) indicated that it was a combination of mother tongue and English that was stipulated in the NPE for teaching IS in Primary IV.

\begin{tabular}{|l|cc|}
\hline Language of Instruction & Numbers of Teachers & Percentage \\
\hline Blank & 2 & $4.9 \%$ \\
\hline English & 36 & $87.8 \%$ \\
\hline Yoruba (mother tongue) & 2 & $4.9 \%$ \\
\hline Combination & 1 & $2.4 \%$ \\
\hline Total & 41 & $100 \%$ \\
\hline
\end{tabular}

Table 7. Teachers' Response on Language of Instruction Stipulated for IS in NPE

(c) Are you aware of the language of instruction in Primary IV?

Twenty-two (58\%) of the teacher-respondents said they were aware of the language of instruction in Primary IV. On the other hand, 16 (42.1\%) of the teachers under study picked the option NO. This question is intertwined with the previous one. They index the fact that some teachers need retraining with regard to what is actually in the National Policy on Education (NPE). It is not a good sign when teachers of whatever cadre indicate that they are not aware of the content of the NPE, the document that is the blueprint for education in a particular country.

\begin{tabular}{|l|c|c|}
\hline & Numbers of Teachers & Percentage \\
\hline YES & 22 & $58 \%$ \\
\hline NO & 16 & $42 \%$ \\
\hline Total & 38 & $100 \%$ \\
\hline
\end{tabular}

Table 8. Teachers' Responses on Awareness of Language of Instruction for Primary IV as Stated in NPE

(d) Do your pupils comprehend your lessons in IS?

The majority of the teacher-respondents examined (34 or 89.4\%) indicated that their pupils comprehended their lessons in whichever language medium was used for teaching IS. Only 4 (11\%) said their pupils did not comprehend their lessons. 


\begin{tabular}{|l|cc|}
\hline & Numbers of Teachers & Percentage \\
\hline Yes & 34 & $89 \%$ \\
\hline No & 4 & $11 \%$ \\
\hline Total & 38 & $100 \%$ \\
\hline
\end{tabular}

Table 9. Teachers' Responses to Pupils' Performance and Adopted Language of Instruction

(e) What language do you recommend for the teaching of IS in primary schools?

According to the findings presented in the table below, none of the teachers indicated the pupils' mother tongue, Yoruba, as the medium of instruction per se. Nine $(22 \%)$ indicated English only as the medium of instruction for IS in primary schools in Nigeria. However, the majority of the teacher-respondents (32, or 78\%) said they preferred MT and English code-switching as a medium of instruction in primary schools, most especially for IS.

\begin{tabular}{|c|c|c|}
\hline Language of Instruction & Numbers of Teachers & Percentage \\
\hline Mother Tongue (Yoruba) & NIL & 0 \\
\hline English & 9 & $22 \%$ \\
\hline $\begin{array}{l}\text { Mother Tongue and } \\
\text { English }\end{array}$ & 32 & $78 \%$ \\
\hline Total & 41 & $100 \%$ \\
\hline
\end{tabular}

Table 10. Teachers' Recommendation for IS Language of Instruction in Primary Schools

\section{Summary, Conclusion and Recommendation}

This paper attempts, first, to argue for the recognition of the mother tongue in the education of the African child generally, and particularly in Nigeria. To support the argument, six primary schools were purposively selected, using teachers and pupils of Integrated Science in Primary IV in two of the four local government areas of Ife: Ife North, Ife Central, Ife East, and Ife South. Considering the time constraint of the "call for paper", we limited the study to six schools (three private and three public primary schools) from Ife East and Ife North LGAs. These schools are representative of the primary schools in Nigeria in particular and Africa in general. As a result, the results obtained from the study can be extrapolated to other schools outside the locales of the study, particularly in bilingual and multilingual speech communities.

From the findings obtained from the study, we are able to recognize the value of the mother tongue in the education of the child in primary schools in Africa. If English cannot be eliminated as the principal language of instruction in primary schools, let it be combined in a code-switching paradigm with the child's mother tongue in the dissemination of knowledge other than English as a subject, such as in Integrated Science and Mathematics. The study recognizes the role that English has been playing as the official language, and the language of instruction, examination, accommodation and social advancement; however, it should be combined with the 
mother tongue so that the child can fully comprehend the concepts in General Science, which is the bedrock of modern technology, national development, and globalization.

\section{References}

Adefila, A. (2008). The implementation of the language component of the National Policy of Education (NPE): The example of the Ife Central Local Government. In O. Emejulu, L. Uwatt, \& A. E. Arua (Eds.), Topical issues in literacy, language and development in Nigeria (pp. 15-28). USA: International Development in Africa Committee (IDAC) of International Reading Association (IRA).

Adekunle, M. (1995). English in Nigeria: Attitudes, policy and communicative realities. In A. Bamgbose, A. Banjo, A. Thomas, \& L. Ayo Banjo (Eds.), New Englishes: A West African perspective (pp. 34-56). Ibadan: Mosuro Publishers; The British Council.

Asiyanbola, A. (2009). English language in Nigerian universities: Sociological, political and educational relevance in the context of globalisation. In D.A Adeyanju (Ed.), The sociolinguistics of English and Nigerian languages (pp 99113). Muechen: LINCOM Europa.

Bamgbose, A. (1971). The English language in Nigeria. In J. Spencer (Ed.), English language in West Africa (pp. 35-48). London: Longman.

Bamgbose, A. (1995). English in the Nigerian environment. In A. Bamgbose, A. Banjo, A. Thomas, \& L. Ayo Banjo (Eds.), New Englishes: A West African perspective (pp 9-26). Ibadan: Mosuro Publishers; The British Council.

Bamgbose, A. (2009). A recurring decimal: English in language policy and planning. In B. Kachru, Y. Kachru, \& C. Nelson (Eds.), The handbook of world Englishes (pp 645-660). Oxford: Wiley Blackwell.

Bilewumo, J.O. (2008). Attitudes towards the use of mother tongue or English as media of instruction: Its implication on literacy development. In B. Kachru, Y. Kachru, \& C. Nelson (Eds.), The handbook of world Englishes (pp. 2-14). Oxford: Wiley Blackwell.

Federal Government of Nigeria (1969). National policy on education. Lagos: Federal Ministry of Education.

Federal Government of Nigeria (1971). National policy on education. Lagos: Federal Ministry of Education.

Federal Government of Nigeria (1988). National policy on education. Lagos: Federal Ministry of Education.

Federal Government of Nigeria (2004). National policy on education. Abuja: Federal Ministry of Education.

Federal Government of Nigeria (2013). National policy on education. Abuja: Federal Ministry of Education. 
Halliday, M.A.K. (1973). Exploration in the functions of language. London: Edward Arnold Publishers.

Hornstein, S. (2005). Beyond print literacy: The importance of multi-literacies in a democratic globalised society. English and the challenges of literacy in the 21st century: Proceedings of the 22nd Annual Conference of the Nigeria English Studies Association (NESA). Lagos, Nigeria: Olivetree.

Jegede, S. (2009). Code-switching as a communicative strategy in multilingual mathematics classrooms in selected primary schools in Ile-Ife (Unpublished M.A. Thesis). Obafemi Awolowo University, Ile-Ife, Nigeria.

Jowitt, D. (1995). Nigeria's national language question: Choices and constraints. In A. Bamgbose, A. Banjo, A. Thomas, \& L. Ayo Banjo (Eds.), New Englishes: A West African perspective (pp. 34-56). Ibadan: Monsuro Publishers; The British Council.

Okebukola, F. (2008). Rethinking the meaning of reforms: Contemporary challenges for practitioners in literacy and language education. In O. Emejulu, L. Uwatt, \& A. E. Arua (Eds.), Topical issues in literacy, language and development in Nigeria (pp. 29-38). USA: International Development in Africa Committee (IDAC) of International Reading Association (IRA).

Onwuka, C., \& Ohia I. (2008). Enhancing literacy empowerment through the mother tongue. In Emejulu, O., L. Uwatt \& A.E. Arua (Eds.), Topical issues in literature, language and development in Nigeria (pp. 53-62). USA: International Development in Africa Committee (IDAC) of International Reading Association (IRA).

Salami, L.O. (2008). "It is still double take": Mother tongue education and bilingual classroom practice in Nigeria." Journal of Language, Identity \& Education, 6(4), 1-23.

Ugwanyi, D. (2008). Of linguistics: Towards a new discourse in the Nigerian language policy. In O. Emejulu, L. Uwatt, \& A. E. Arua (Eds.), Topical issues in literacy, language and development in Nigeria (pp. 39-52). USA: International Development in Africa Committee (IDAC) of International Reading Association (IRA). 